Santa Clara University

Scholar Commons

Psychology

College of Arts \& Sciences

2005

\title{
Do faultlines hurt or help? exploring distance, identity, task conflict, and individual performance in diverse groups
}

Katerina Bezrukova

SantaClara University, ybezrukova@scu.edu

Karen A. Jehn

Elaine Zanutto

Sherry M.B. Thatcher

Follow this and additional works at: http://scholarcommons.scu.edu/psych

Part of the Psychology Commons

\section{Recommended Citation}

Bezrukova, Katerina; Jehn, Karen A.; Zanutto, Elaine; and Thatcher, Sherry M.B., "Do faultlines hurt or help? exploring distance, identity, task conflict, and individual performance in diverse groups" (2005). Psychology. Paper 2.

http://scholarcommons.scu.edu/psych/2

2005 - The 18th Annual Conference of the IACM, Seville, Spain Dates: June 12-June 15, 2005 Location: Seville, Spain http://www.iacm-conflict.org/

This Presentation is brought to you for free and open access by the College of Arts \& Sciences at Scholar Commons. It has been accepted for inclusion in Psychology by an authorized administrator of Scholar Commons. For more information, please contact rscroggin@scu.edu. 


\title{
DO FAULTLINES HURT OR HELP? EXPLORING DISTANCE, IDENTITY, TASK CONFLICT, AND INDIVIDUAL PERFORMANCE IN DIVERSE GROUPS
}

\author{
Katerina Bezrukova \\ Department of Psychology \\ Rutgers University \\ 311 N. Fifth Street \\ Camden, NJ 08102 \\ Phone: 856-225-6120, Fax: 856-225-6602 \\ E-mail: bezrukov@camden.rutgers.edu \\ Karen A. Jehn \\ Social and Organizational Psychology \\ Leiden University \\ Wassenaarseweg 52 \\ Leiden 2333 AK \\ The Netherlands \\ E-mail: jehnka@fsw.leidenuniv.nl \\ Elaine Zanutto \\ The Wharton School \\ University of Pennsylvania \\ Philadelphia, PA 19104-6370 \\ E-mail: zanutto@wharton.upenn.edu \\ Sherry M.B. Thatcher \\ Management Information Systems Dep't \\ University of Arizona \\ Tucson, AZ 85721 \\ Phone: 520-621-2255, Fax: 520-621-2433 \\ E-mail: sherryt@bpa.arizona.edu
}

Type of the paper: Empirical 


\title{
DO FAULTLINES HURT OR HELP? EXPLORING DISTANCE, IDENTITY, TASK CONFLICT, AND INDIVIDUAL PERFORMANCE IN DIVERSE GROUPS
}

\begin{abstract}
We introduce the concept of faultline distance that reflects the extent to which subgroups formed by faultlines diverge as a result of accumulated differences across them (e.g., two members of age 20 are closer in age to two members of an opposing faultline of age 25 than of two members of age 50). We further extend faultline theory by showing how different faultline bases (information-based and social category faultlines) have differential effects on outcomes. Using a sample of 76 workgroups from a Fortune 500 information processing company, we examine the relationships between group faultlines, shared identity, work-related conflict, and multiple individual performance indicators. The results reveal that members of groups with strong information-based faultlines had high levels of performance ratings, while members of groups with strong social category faultlines had low levels of bonuses. Faultline distance further exacerbated the negative effects in groups with strong social category faultlines and reversed the positive effects in groups with information-based faultlines. A sense of strong superordinate identity among group members enhanced members' performance. Finally, mediated moderation was confirmed for the groups with strong social category faultlines; such groups had low levels of conflict which then resulted in low levels of bonuses.
\end{abstract}

Key words: group faultlines, individual performance, work-related conflict, and shared identity 


\section{DO FAULTLINES HURT OR HELP? EXPLORING DISTANCE, IDENTITY, TASK CONFLICT, AND INDIVIDUAL PERFORMANCE IN DIVERSE GROUPS}

Advances in communication and technology and redistributing product innovations across global $R \& D$ have created numerous opportunities for diverse workgroups to thrive. Organizations capitalize on groups comprised of members who differ on demographic characteristics (e.g., gender, race, country of origin, education, skills) as a way of reaching new markets, securing essential but scarce expertise, and remaining competitive (Offerman and Gowing, 1990; Thomas and Ely, 1996). They have lured people from around the world whose cultural, religious, educational, etc. differences are also highly salient in globe-spanning workgroup contexts. While the prevalence of diverse groups would seem to indicate their effectiveness, many groups have been suffering from misunderstanding, destructive conflict, ineffective communication, and other problems related to members' differences (Pelled, 1996; Thomas and Ely, 1996). Because effective diversity management has become a crucial requirement for business success, the question of whether diversity helps or harms has attracted a great deal of attention from both managers and researchers (e.g., Jackson, et al., 1992; Jehn, Northcraft, and Neale, 1999; Polzer, Milton, and Swann, 2002).

Yet, recent reviews of group diversity and relational demography research have reported extremely mixed empirical results (c.f., Riordan, 2000; Williams and O'Reilly, 1998). Negative effects of diversity have been attributed to conflict that arises from perceived differences amongst team members (e.g., Tsui, Egan, and Xin, 1995) which interferes with performance (e.g., Pelled, 1996). Positive effects of diversity have been explained by cognitive resource diversity which suggests that the breadth of perspectives that diverse group members embrace enhances performance (e.g., Ancona and Caldwell, 1992; Gruenfeld, Mannix, Williams, and Neale, 1996). These competing theoretical arguments, along with inconsistent empirical results, have led to a lack of consensus regarding a valid conceptual framework and have stressed the need for a more comprehensive theory. One of the most intriguing advances along these lines comes from the group faultlines theory introduced by Lau and Murnighan (1998).

Faultlines occur when group members align along one or more demographic characteristics causing a group to split into fairly homogeneous subgroups (adapted from Lau and Murnighan, 1998). According to the theory, the compositional dynamics of multiple attributes aligned across group members influences behavior; for example, a clean-cut 
demographic alignment in a group (e.g., group members are aligned such that all the men are white and all the women are Hispanic) may accentuate managerial coalitions and harm group functioning and effectiveness. While prior theorizing about faultlines has focused on the concept of faultline strength (defined as the extent of demographic alignment across members within a group (e.g., Lau and Murnighan, 1998; Thatcher, Jehn, and Zanutto, 2003)), another important aspect of faultlines - differences between aligned subgroups - has been generally ignored. We therefore, discuss the concept of faultline distance and introduce an extended theory of group faultlines in the following section.

Most recently, faultline theory has been also criticized for the lack of clarity with respect to how different demographic variables may contribute to the development of faultines and whether faultline theory takes into account the nature of diversity (Jehn et al., 1999; Polzer et al., 2002). The theoretical argument has been that while visible (also described as relations-oriented; Jackson, Joshi, and Erhardt, 2003) characteristics (age, race, and gender) are easily detectable, more accessible, and likely to induce responses such as in-group biases and conflict (Thatcher and Jehn, 1998; Tsui, Egan, and O’Reilly, 1992), non-visible (or task-oriented) characteristics (education, tenure, and functional background) are more relevant to the tasks performed by a group and hence, have a stronger impact on task-related group processes (Pelled, Eisenhardt, and Xin, 1999; Webber and Donahue, 2001). We further pursue the theoretical development of faultlines by showing how social category (visible) and information-based (non-visible) characteristics serve as a basis for developing the respective types of faultlines within a group. We argue that subgroup processes may not always be negative and the nature of members' characteristics (social category vs. informational) may trigger different processes (which may be more appropriate to some tasks than others). For example, subgroups based on informational faultlines (members' alignment along education, tenure and function) are more likely to result in a detached information perspective (Gruenfeld et al., 1996) and operate in workgroups as "healthy divides" that stimulate effective decision making processes and foster team members' learning (Gibson and Vermeulen, 2003). We hence, extend faultline theory by predicting the distinct effects of different bases of faultlines on individual performance outcomes.

Group faultlines formed as a result of demographic alignment of group members suggest that subgroup identifications and superordinate identity may create a condition for crosscategorization within a common-goal group and then, either aggravate or alleviate the faultline 
dynamics. Cross-cutting categories are developed when 'others' can be simultaneously categorized as ingroup (members of a larger group) or outgroup (members of another subgroup) based on multiple dimensions (Brewer, 1996; Hewstone, 1996). Although some theorizing about identification processes and subgroup salience exists (c.f., Brewer, 2000; Crampton and Hinds, 2004; Crisp and Hewstone, 2001), the possibility of cross-categorization effects and common ingroup identity in the context of faultlines remains untested. While group conflict that focuses on conflict within a group or between groups has also been a main focus of organizational behavior and social psychology (e.g., Gaertner, Dovidio, Banker, Houlette, Johnson, and McGlynn, 2000; Jehn, 1997; Kessler and Mummendey, 2001; Levine and Moreland, 1990; Pelled, 1996) we believe that the dynamics by which a group splits into subgroups, and the conflict that arises from faultlines within the common-goal group have been somewhat ignored. Thus, we integrate conflict into our model and explore its mediating effects in the relationship between faultlines and performance outcomes (Lau and Murnighan, 1998). In conclusion, we contribute to the literature on group identity and organizational conflict by firstly examining the role of superordinate team identity and conflict on faultline dynamics and secondly by providing an empirical test of the theory in the field.

\section{EXTENDING GROUP FAULTLINE THEORY}

\section{Faultline Distance}

To conceptualize faultline distance and add to our understanding of the faultline theory, we first draw upon the social dominance theory (c.f., Sidanius and Pratto, 1999), which suggests that group members share a schema that cognitively constructs other out-group members in a hierarchy by agreeing what groups are to be kept at a greater distance than others (Hagendoorn, 1995; Mullick and Hraba, 2001). Research further suggests that group members construct social representations based on relative distances of demographic attributes (e.g., Hraba, 1989; Hraba, Radloff, and Gray-Ray, 1999). Attempts have been made to investigate the effects of demographic distances between two individuals, an individual and others within a group, and several groups (e.g., Bogartus, 1925; McCauley et al., 2001; Tsui et al., 1992). Bogartus (1925) and Moreno (1934) identified the relative distance between individuals by placing them into predefined social groups to assess the level of intergroup contact. Relational demography research has also focused on an individual's dissimilarity or his or her demographic distance from others 
within a group to investigate the effects of group heterogeneity (e.g., Blau, 1977; Pelled, 1996; Tsui et al., 1992). Studies of ethnic group relations have shown that individuals hold socialdistance beliefs about ethnic groups different from themselves (Hagendoorn, Drogendijk, Tumanov, and Hraba, 1998; Mullick \& Hraba, 2001). The fundamental limitation of these approaches is that they assess only one characteristic at a time and fall short of accounting for the differences between group members on multiple aligned demographic attributes.

Prior conceptualizations of faultlines operating in demographically diverse workgroups have focused on the construct of faultline strength (Lau and Murnighan, 1998; Thatcher et al., 2003). Faultline strength, as defined by the theory, captures how many demographic attributes align within a group or, in other words, how cleanly a group may split into two homogeneous subgroups (Thatcher et al., 2003). An example of a group with a strong faultline would be a fourperson group consisting of two white male employees who are 21 years old and two black female employees who are 50 years old. In this group, the demographic alignment across members is clear because two homogenous subgroups may emerge based on group members' similarities in gender, race, and age; according to Lau and Murnighan (1998), there is a strong faultline within the group. An example of a group with weak faultline strength would be a fourperson group consisting of one 21-year old Asian female, one 21-year old white male, one 25year old black female, and one 25-year old Native American Indian male. In this latter group, the demographic alignment across members is not as clear as in the first example and faultline strength is weak because two different subgroup possibilities exist: those based on gender or age.

Existing faultline theory ignores the extent to which subgroups diverge as a result of accumulated differences across aligned subgroups - we label this aspect faultline distance between the subgroups. Faultline distance allows us to compare homogeneous subgroups emerging from faultlines by taking into account multiple demographic attributes. In our example, the two members of age 21 in the second group are closer in age to two members of an opposing faultline of age 25 than of two members of age 50 as in the first group, thereby creating a smaller faultline distance across emerging subgroups. Given the varying differences in age, the group composition and processes of these two groups will be very different. ${ }^{1}$

\footnotetext{
${ }^{1}$ While faultline distance seems to most simply refer to differences in age, tenure (years of experience), and other continuous variables, we argue that distance is also applicable for categorical variables. For example, if group 1 has two White members and two Asian members and group 2 has four White members, group 1 does have faultline
} 
We thus, argue that group faultlines can be viewed as a multidimensional concept that reflects at least two properties: faultline strength (the number of demographic attributes that group members align on) and faultline distance (how far apart these aligned subgroups are from each other). We propose that the distance between subgroups, in addition to faultline strength, influences the interaction of members within a group and subsequent behaviors and outcomes. Thus, our extended approach suggests that we should take into account the basis for faultline formation and simultaneously consider multiple attributes of group members, the extent to which members align along these attributes, and finally, the distances between the resulting subgroups of aligned members. This extension to faultline theory provides a more comprehensive view of diversity and demographic alignment than those presented by previous work.

\section{Social category and information-based faultlines}

Jehn and her colleagues (1999) have stressed the value in distinguishing between forms of diversity (e.g., those based on social categories and those based on informational categories). Social category characteristics are observable attributes such as race/ethnic background, nationality, sex, and age (Cummings, Zhou, and Oldham, 1993; Jehn et al., 1999). While members' differences on these characteristics may not be relevant to a given task, they do shape people's perceptions and behaviors through mechanisms of categorization and prejudice (Pelled, 1996). Regardless of the accuracy of the categorizations, they may lead to conflict if individuals do not live up to the expectations of others based on these categories. Informational characteristics are underlying attributes of individuals (such as work experience and education) which, although not immediately detectable, are important in the completion of a task (Jehn et al., 1999). They are less visible and therefore, less prone to interpersonal prejudice and stereotyping than social category characteristics. A wider array of views, skills, and information that members bring to a group might have positive implications on workgroup outcomes (Gruenfeld et al., 1996). Researchers have suggested that these two types of diversity may differently impact group processes and performance due to their degree of job-relatedness (Webber and Donahue, 2001).

Faultlines form when differences on one dimension produce notable schisms that are then coupled with schisms on other dimensions (Hambrick, Li, Xin, and Tsui, 2001). As a result, 
ingroups and outgroups emerge based on the faultlines. The nature of the ingroup and outgroup distinction becomes crucial to the future functioning of groups. For example, such schisms could occur along readily observable social category characteristics (e.g., nationality, gender, age), or along less visible, informational attributes (e.g., company tenure, education), in that way creating a possibility for developing either a social category or information-based faultline. Social category faultlines are hypothetical dividing lines that split a group into subgroups based on social category demographic characteristics (e.g., age, race, gender). Subgroups formed along social category characteristics such as race, gender, or age may set in motion mechanisms such as stereotyping and prejudice (Messick and Mackie, 1989). Information-based faultlines are hypothetical dividing lines that create subgroups based on informational characteristics (e.g., work experience, tenure). Subgroups that form based on information-based faultlines are more likely to result in a detached information perspective, which increases flexibility of group members' thoughts (Nemeth, 1986) and facilitates effective pooling of information and integrating of alternative perspectives (Gruenfeld et al., 1996). Such informational splits can operate in workgroups as "healthy divides" that stimulate effective decision making processes and foster team learning (Gibson and Vermeulen, 2003) by effectively utilizing the teams' cognitive resources. This extends Lau and Murninghan's (1998) original conceptualization of faultlines as it differentiates between the effects of different bases for subgroup formation (alignments along informational or social category characteristics) on processes and outcomes.

\section{FAULTLINES, GROUP IDENTITY, TASK CONFLICT AND OUTCOMES Group Faultlines and Outcomes}

Lau and Murnighan (1998) propose that faultlines will have a negative effect on group outcomes based on processes such as potential conflict and communication problems. Social category membership provides a particularly salient basis for categorizing members into ingroups and outgroups (Jehn et al., 1999; Pelled et al., 1999). The alignment of demographic attributes based on similarity of group members across social category characteristics (age, race, and gender) is likely to amplify in-group/out-group membership and sharpen the boundary salience around emerging subgroups. The negative effects of stereotyping, in-group favoritism and out-group hostility can cause conflict and dislike to surface, and lead to decreased cohesion and social integration (Mackie, Devos, and Smith, 2000; Tajfel \& Turner, 1986). This lessens the 
frequency of interactions and information exchanges between members of different subgroups emerging from social category faultlines, which in turn, may lead to individual performance losses because both the amount of information and the access to the resource pool is reduced (Clement and Schiereck, 1973; Freidman and Podolny, 1992). Furthermore, the "us versus them" mentality of subgroups is likely to make it easy for one subgroup to blame the other subgroup for mistakes (Hogg, 1996). It also leads to power differentials allowing a subgroup to dominate discussion and prevent the participation of others (Gillespie, Brett, and Weingart, 2000; Johnson and Johnson, 1994). Tension and personal attacks within a group resulting from these processes can cause further dissatisfaction among group members (e.g., Amason and Schweiger, 1994; Jehn, 1994).

Hypothesis 1 (H1): Social category faultline strength will negatively affect individual performance and satisfaction.

While many researchers may argue that similar logic (i.e., the social categorization argument) can be applied to the groups with alignments along informational characteristics (education, tenure, functional background), we believe that expectancy effects emerging from information-based alignment may overrule the social categorization effects. Expectancyviolation theory, in part, suggests that the violations of category-based expectations (or the experience of unexpectedness) may influence affective reactions and promote negative evaluations of out-group members (Bettencourt, Dill, Greathouse, Charlton, and Mulholland, 1997). In groups with information-based alignments, the fact that members of another subgroup have different functional backgrounds would be consistent with the fact that they also have different levels of education and work experiences. Because of subgroup formation, members become more aware of their differences and are expected to be different along informational lines. This elicits less uncertain and ambiguous environments in which members are more likely to accept their informational differences (Rink and Ellemers, 2003). As a result, they may freely express their ideas and engage in a thorough, intensive elaboration of the problem. Synthesis of ideas that are superior may emerge (Schweiger and Sandberg, 1989; Schwenk, 1990) and thus, reinforce individual performance. Less ambiguous environments should also promote feelings of predictability, tolerance, coherence and control (Schneider, Salvaggio, and Subirats, 2002). These feelings have been shown to foster positive response and satisfaction (Hogg, 1996). 
Hypothesis 2 (H2): Information-based faultline strength will positively affect individual performance and satisfaction.

\section{The Moderated Effects of Faultline Distance}

As previously discussed, simple alignment of members along social category attributes induces awareness of membership into separate and distinct subgroups and is a sufficient condition to initiate unproductive interactions across them. These interactions, however, may become more antagonistic if members of one subgroup think they are extremely different from members of another subgroup. We therefore, propose that faultline distance will exacerbate the negative effects of social category faultline strength in diverse groups.

Although category-based expectations are likely to be met in groups with informationbased alignments, the distance between emerging subgroups may reverse initially positive effects of strength and promote negative affect. For example, as members across subgroups become more distant, boundaries around subgroups happen to be more salient and some subgroups are automatically placed on the status hierarchy relative to the dominant subgroup (Asante and Davis, 1985). Within this status hierarchy, the low-status subgroups are not expected to contribute as much as high-status subgroups (e.g. Kimble and Musgrove, 1988; Plaks and Higgins, 2000), thereby declining the individual level of contribution. Moreover, due to the emerging power differentiation, subgroup formation may restrict access to important resources and hence, deprive another subset of group members who do not belong to the dominant coalition (Mannix, 1993; Sherif, 1966). Distancing across subgroups produced by either social category or information-based faultlines suggests inevitable process and performance losses. We further propose that the possible inequities across distant subgroups formed by any type of faultlines may lead to decreased satisfaction (Gillespie et al., 2000).

Relational demography research provides evidence of productivity losses in workgroups occurring as a result of greater distance between people or subgroups (Jackson et al., 1991; Tsui et al., 1992). For example, Wagner, Pfeffer, and O'Reilly (1984) found that larger demographic distances among the vice-presidents in 30 firms were associated with higher levels of turnover. Tsui and colleagues (1992) demonstrated that group members were more satisfied with their membership in a group when they fell within the boundary of a specific age category. Jackson et al. (1991) reported that larger differences in educational level among top management teams were significantly related to turnover behavior. Thus, based on the above theorizing: 
Hypothesis 3 (H3): Faultline distance will moderate the relationship between faultline strength and individual performance (and satisfaction); that is, if there is a large distance across subgroups formed by faultlines, strength is more likely to result in lower levels of performance and satisfaction than if there is a small distance across subgroups.

\section{Organizational Identity}

A great deal of research has been concerned with understanding the role of common ingroup identity as one of the mechanisms for bias reduction in the context of intersubgroup relations (e.g., Brewer and Miller, 1984; Gaertner et al., 1993; Hewstone, Rubin, and Willis, 2002). According to the theory of common ingroup identity, individuals who strongly identify with their group are both committed to that identity and hold it as primary (Dovidio, Kawakami, and Gaertner, 2001; Gaertner, Dovidio, and Bachman, 1996). Gaertner et al (1989) have found consistent evidence for their Common Ingroup Identity Model as an explanatory mechanism for reducing intergroup bias. They posit that recategorization from two-groups (ingroup/outgroup) to a one-group (or superordinate) representation of the group can lead to a decrease in intergroup bias across subgroups. In a high superordinate identity team, the former intersubgroup boundaries become weak, and instead new, inclusive team-based boundaries become important in the minds of members, reducing the adverse effects of subgroup identities (Brewer and Miller, 1984; Thatcher and Jehn). This superordinate identity influences the ability of group members to put less focus on attributes related to social categories (Hodson and Esses, 2002), thereby inhibiting the potentially negative effects of faultline distance.

Given that members may identify with multiple demographic categories (Brewer, 1996; Randel, 2002), cross-categorization theory (Brewer, 2000; Crisp and Hewstone, 2000) also provides support for a double moderating effect of superordinate identities. Cross-categorization is based on cross-cutting demographic categories within groups, where 'others' can be simultaneously classified as in-group or out-group members based on multiple dimensions (Hewstone, Rubin, \& Willis, 2002). For example, the crossing of one dimension of categorization (e.g., gender: female - male) with a second (e.g., profession: engineer sociologist) will result in four crossed groups (female - engineer / female - sociologist / male engineer / male - sociologist) with which members could identify. Establishing a common superordinate identity may lead to a greater emphasis on similarities and the placement of multiple members into ingroup categories (Gaertner et al., 1993). Ideally, members will focus on 
a superordinate identity which cuts across demographically-aligned subgroup members, thus decreasing negative effects of ingroup/outgroup distinctions such as stereotypes, prejudices, and withholding of information and resources (Brewer, 2000). In an organizational setting, the highest superordinate identity of relevance to a team is that of the organization. Therefore, crosscutting social identities activated by a strong superordinate identity (e.g., organizational identity) may reduce bias by decreasing perceived differences (Ensari and Miller, 2001; Hewstone and Brown, 1986; Wolsko et al., 2000) across subgroups emerging from either type of faultlines. Therefore, we suggest the following double moderating effect of organizational identity on the relationships between social category or information-based faultlines and individual-level outcomes.

Hypothesis 4 (H4): A three-way interaction between faultlines strength, distance, and organizational identity is expected, such that individuals in groups with strong faultlines (both strength and distance) and high levels of organizational identity are more likely to have higher levels of individual performance and satisfaction than individuals in groups with lower levels of identity.

\section{The Role of Task Conflict}

Research and theorizing on group diversity suggests some form of the basic inputprocess-outcome model of group effectiveness (e.g., Guzzo and Shea, 1992; Williams and O'Reilly, 1998). In a simple form of this model, group composition (e.g., faultlines) influences patterns of interaction within a group (e.g., conflict, social integration) which, in turn, affect outcomes (e.g., performance, satisfaction) (Bunderson and Sutcliffe, 2002). Consistent with this idea, our research empirically examines the mediated moderating relationships that are assumed to exist (e.g., Muller, Judd, and Yzerbyt, 2005; Pelled et al., 1999; Williams and O'Reilly, 1998) between faultlines, identity, task conflict, and outcomes. Task conflicts are defined as disagreements between members around ideas and opinions about the task being performed (Jehn, 1995).

When group members align along informational characteristics, they tend to exhibit similar viewpoints within each subgroup and display different opinions across subgroups. This is due to different approaches to problem solving caused by differences in training and experiences (Bantel and Jackson, 1989; Pelled, 1996; Gruenfeld et al. 1996). Literature on minority influence suggests that information sharing in diverse groups depends on the extent to which group 
members are provided with social support (c.f., Allen and Levine, 1971; Bragg and Allen, 1972). In groups with strong informational faultlines, members may freely express their ideas and actively engage in open discussion of divergent perspectives across subgroups because they have support from within their own subgroup (Lau and Murnighan, 1998; Phillips, 2003; Swann et al., 2004). Intensified by the distance effect, subgroup members may have a strong tendency toward conformity to the opinion, idea, or perspective favored by their own subgroup (Baron, Kerr, \& Miller, 1993) and a need to distinguish their views from the other subgroup (Brewer, 2000; Hogg, Turner, and Davidson, 1990). These processes cause group members to exhibit intense polarization around ideas and thoughts across subgroups (Ancona, 1990). We therefore argue that individuals in such groups will experience high levels of conflict over task-related issues. Task conflict can also be a strategy to counteract the biased information-seeking of consensusbased subgroups (Schulz-Hardt, Jochims, \& Frey, 2002). Task conflict may also improve individual decision quality because the synthesis that emerges from the conflict is superior to the individual solutions themselves (Schweiger and Sanberg, 1989; Schwenk, 1990). Specifically, task conflict has been shown to lead to problem solutions characterized by more creativity and higher quality (Ancona and Caldwell, 1992; De Dreu and Van de Vliert, 1997; Nemeth and Kwan, 1987). However, these gains in decision quality can be accompanied by negative side effects; for example, research has shown that members of groups debating divergent opinions have low levels of satisfaction (Amason, 1996; Jehn, 1997; Schwenk and Cosier, 1993).

Hypothesis 5 (H5): We expect that the effect of information-based faultlines strength on individual performance and satisfaction depends on the distance between subgroups. We further expect that the moderating information-based faultline strength effect should be mediated via task conflict. That is, in groups with high information-based faultline distance, high information-based faultline strength should lead to high levels of task conflict, which would promote higher levels of performance but lower levels of satisfaction than in groups with high information-based faultline strength and low information-based distance.

As mentioned earlier, members of distant subgroups formed by social category faultlines develop negative stereotypes towards outgroup members. These negative effects of stereotyping, in-group favoritism and out-group hostility sharpen the boundary salience around subgroups causing antagonism and animosity (Labianca, Brass, and Gray, 1998). Researchers propose that 
anxiety and threat create cognitive interference with task accomplishment (Pelled, 1996) and detract a group from critical task-related work (Jehn, 1997). For example, group members in organizations withhold divergent views due to a number of reasons such as formal or informal communication barriers (Baron and Greenberg, 1989) and conformity pressures within the group (Janis, 1972). They may be also reluctant to pool the unique personal information that could potentially enrich their individual performance (Gruenfeld et al., 1996; Phillips et al., 2004) and hence, they miss opportunities to utilize all available assets. This may also lead to less positive and satisfying interactions for the groups with strong social category faultlines.

Hypothesis 6 (H6): We expect that the effect of social category faultline strength on individual performance and satisfaction depends on the distance between subgroups. We further expect that the moderating social category faultline strength effect should be mediated via task conflict. That is, in groups with high social category faultline distance, high social category faultline strength should lead to low levels of task conflict, which would negatively affect performance and result in lower levels of satisfaction than in groups with high social category faultline strength and low social category faultline distance.

\section{METHOD}

\section{Research Site and Sample}

Our sample includes 76 groups in a large corporation within the information processing industry. This company specializes in mailing and document processes and technologies that save customers' time and money and enhance their security. In this company, employees work in groups in a range of divisions such as corporate administration, finance, sales, product development, software systems, and manufacturing. We identified the workgroups using a reporting system developed by the company, as well as the information about the structure of the divisions and departments provided by key senior staff. We verified that these were actual working groups (i.e., they interacted on a day-to-day basis, were task interdependent, identified each other as group members, and were seen by others as workgroups) by interview and observation. We were informed by key senior staff and employees that "groups" of one or two employees or groups with over sixteen employees were not actual working groups. This is consistent with our definition of a group (see above) and with group process theories regarding 
group size. Therefore, we eliminated such "groups" from our analysis leaving a sample of 76 groups and 567 individuals with complete demographic and performance data. The age of employees ranged from 26 to 69 years with a mean of 47 years. The employees were $72 \%$ male. The majority of employees (88\%) were white; $6 \%$ were African American, $2 \%$ Asian, and the remaining are Hispanic. The level of education ranged from grade school to the $\mathrm{Ph}$. D. level. Tenure with the company ranged from less than one year to 44 years with a mean of 14 years. Functional background included administrative, customer service, finance, and marketing groups.

\section{Measures}

Group Faultlines. We measured social category and information-based faultlines along two social category characteristics (gender and age) and along two informational characteristics (education and tenure). These demographic variables were chosen based on previous research on group diversity (Tsui et al., 1992) and availability in the dataset. To measure faultline strength, we use a faultline algorithm and a rescaling procedure developed by Thatcher, Jehn, and Zanutto (2003). Thatcher et al's Fau measure calculates the percent of total variation in overall group characteristics accounted for by the strongest group split by calculating the ratio of the between group sum of squares to the total sum of squares. We calculated the faultline strength scores considering only splits in which each subgroup has at least two members, thus excluding "token" splits (i.e., subgroups consisting of only one member). Possible values of faultline strength ranged from .398 to .936 for information-based faultlines and from .386 to .954 for social category faultlines in our dataset.

To extend prior conceptualizations and operationalizations of group faultlines, we also measured faultline distance, in other words, how far apart the two resulting subgroups are from each other on social category (age and gender) and informational (level of education and tenure with the company) characteristics. This faultline distance measure takes into account multiple characteristics of group members by calculating scores for both continuous and categorical variables simultaneously, hence extending existing measures of faultline strength (Thatcher et al., 2003). The faultline distance measure is adapted from multivariate statistical cluster analysis (e.g., Morrison, 1967; Jobson, 1992; Sharma, 1996) and is calculated as a distance between centroids (the Euclidean distance between the two sets of averages): 
$D_{g}=\sqrt{\sum_{j=1}^{\mathrm{P}}\left(\overline{\mathrm{x}}_{1 j^{*}}-\overline{\mathrm{x}}_{2 j^{*}}\right)^{2}}$, where centroid (vector of means of each variable) for subgroup $1=\left(\overline{\mathrm{X}}_{l l}, \overline{\mathrm{X}}_{12}, \overline{\mathrm{X}}_{13^{\prime}}, \ldots, \overline{\mathrm{X}}_{1 P}\right)$, centroid for subgroup $2=\left(\overline{\mathrm{X}}_{2 l}, \overline{\mathrm{X}}_{22^{2}}, \overline{\mathrm{X}}_{23^{\prime}}, \ldots, \overline{\mathrm{X}}_{2 P}\right)$.

Faultline distance can take on values between 0 and $\infty$, with larger values indicating larger distance between the resulting subgroups. Possible values of faultline distance ranged from .428 (weak faultline distance) to 2.903 (very strong faultline distance) for informationbased faultlines and from .544 to 3.019 for social category faultlines in our dataset. See Appendix 1 for the calculations. The combination of the faultline strength score and the faultine distance score can provide useful information not yet captured in any past demographic or diversity research that we are aware of.

\section{Content Analysis}

To generate measures of task conflict, organizational identity, and satisfaction, we content-analyzed company documents that were part of a human resource-sponsored program. As a module of this program designed to help managers and supervisors of workgroups in their planning, employees completed Development Reports regarding their workgroups. The Reports capture the dominant group processes in work groups, particularly including how strongly individuals identify with their groups, how much task conflict they experience, and how much they are satisfied with group performance. Employees submit their information directly over the corporate intranet or via the internet. This information is confidential and available only to the employee, his or her direct manager and a selected group of Human Resource personnel.

Following the method of Jehn and Werner (1993), two independent raters conducted the key word searches on all individual responses, reviewed the surrounding context and coded the text for each variable of interest as defined by theory. In particular, the raters jointly went through the first few individual responses to develop the coding guidelines (see Appendix 2 for the details). They coded the rest of the responses individually. The raters followed guiding questions to evaluate each variable of interest for each individual response on a scale from 1 (the least) to 7 (the most). The inter-rater agreement ranged from $89 \%$ to $97 \%$ on the variables and was determined by checking the number of times that the raters agreed upon the score which they assigned to an individual response. When raters rated a response farther than 1 point apart, they discussed the response until they reached an agreement and then, they refined their coding rules. 
Task Conflict. The raters defined the extent or degree of task conflict indicated by the employee on a scale from 1 (no conflict) to 7 (extreme amount of conflict). An illustrative example from the data demonstrating an extreme task conflict is provided below.

“...customer service and employee training and communications are difficult, stressed. XXX [a group of employees] does not support this with different objectives, philosophy's, etc... Resources, including IT, people, Telecomm Voice and Data are stressed and pulled in different directions. We had conversations with appropriate $\mathrm{Sr}$ Mgt on org structure to balance competitiveness and the need to reduce costs with the need to run the business as efficiently as possible with well trained people..."

Organizational identity. We operationalized the degree of superordinate identity as the

extent to which a group member identifies with his or her group and feels as a part of this group.

The raters coded the variable using a seven point Likert scale $(1=$ low team identity, $7=$

extremely high team identity). The following extract from the data illustrates a strong sense of identity:

“...This has historically been a successful group, we need to keep it that way. Regular staff meetings. 1-2 a month. every other staff meeting there will be a staff dinner. First off-site will be held on 6/10 and 6/11. This is an effort to get the staff to know each other better. (These are all new players to this staff)... Making this connection will not only prove as a morale booster in the function but also get a very bright bunch of professionals to increase shareholder value."

Satisfaction. It refers to how well a member of a group believes the group as a whole does in accomplishing group tasks. The raters coded both variables using a seven point Likert scale $(1=$ extremely dissatisfied, $7=$ extremely satisfied $)$. An illustrative example from the data demonstrating satisfaction is provided below.

“...Sustain strong no.1 market position in core mail finishing while accelerating growth in systems, professional services, and other new business initiatives. Our ability and effectiveness in influencing worldwide posts to implement favorable policies are critical to achieving business objectives. Continue to deliver strong bottom line results through process reengineering while simultaneously implementing the IS information support platform... Hire project manager to drive implementation of best-in-breed product development practices and metrics..."

\section{Performance}

We measure individual performance based on employees' archival bonus data. Bonus amounts are the actual bonus amounts paid out for the year and are calculated based on group performance. Performance ratings are the codes indicating whether the productive output of the individual meets or surpasses specific performance goals and are associated with an employees' 
performance review (e.g. 5 refers to outstanding performance, and 1 refers to unsatisfactory).

\section{RESULTS}

Table 1 displays means, standard deviations, and correlations among all variables. We examine the relationships between faultlines, organizational identity, task conflict and outcomes further using hierarchical linear modeling (HLM).

\section{INSERT TABLE 1 ABOUT HERE}

\section{The Main Effect and Moderated Effects of Faultline Strength and Distance}

Table 2 shows the results of HLM analyses testing the main effects of faultline strength and moderated effects of faultline distance. Step 1 of the HLM includes the main effects of the faultline strength, Step 2 includes the main effects of both - faultline strength and distance. Step 3 includes the interaction term. In support of Hypothesis 1 predicting that social category faultline strength will negatively affect individual performance and satisfaction, social category faultline strength was negatively related to bonuses (Beta $=-1.295, p=.080$ ) and performance ratings (Beta $=-.630, p=.049$ ). Supporting Hypothesis 2 , information-based faultline strength was positively associated with performance ratings (Beta $=.947, p=.008)$.

Hypothesis 3 predicted that faultine distance will moderate the relationship between faultline strength and individual performance (and satisfaction); that is, if there is a large distance across subgroups formed by faultlines, strength is more likely to result in lower levels of performance and satisfaction than if there is a small distance across subgroups. In support of H3, social category and information-based faultline distance moderated the effects of faultline strength on bonuses and satisfaction.

-INSERT TABLE 2 ABOUT HERE

\section{The Double Moderating Effects of Organizational Identity}

We conducted a series of HLM analyses to test Hypothesis 4 predicting a three-way interaction between faultlines strength, distance, and organizational identity, such that individuals in groups with strong faultlines (both strength and distance) and high levels of organizational identity are more likely to have higher levels of individual performance and satisfaction than individuals in groups with lower levels of identity. Step 1 includes the main effects of faultline strength, distance and identity, step 2 includes three two-way interaction terms, and step 3 includes a three-way hypothesized interaction (faultline $\mathrm{x}$ strength $\mathrm{x}$ distance $\mathrm{x}$ 
identity). In support of $\mathrm{H} 4$, there were two significant three-way interactions: one was between social category faultline strength, distance and identity on performance ratings and another was between information-based faultline strength, distance, and identity on bonuses.

\section{The Mediating Moderated Effects of Identity and Task Conflict}

The three regression equations suggested by Baron and Kenny (1986) and modified by Muller, Judd, and Yzerbyt (2005) were performed to test the mediating moderated role of identity and task conflict. Following Hypothesis 5, we expected that the effect of informationbased faultlines strength on individual performance and satisfaction depended on the distance between emerging subgroups. We further expected that the moderated information-based faultline strength effect should be mediated via task conflict. That is, in groups with high information-based faultline distance, high information-based faultline strength should lead to high levels of task conflict, which would promote higher levels of performance but lower levels of satisfaction than in groups with high information-based faultline strength and low information-based distance. The mediating moderation was not confirmed for this hypothesis.

Following Hypothesis 6, we expected that the effect of social category faultline strength on individual performance and satisfaction would depend on the distance between emerging subgroups. We further expected that the moderated social category faultine strength effect should be mediated via task conflict. That is, in groups with high social category faultline distance, high social category faultline strength should lead to low levels of task conflict, which would negatively affect performance and result in lower levels of satisfaction than in groups with high social category faultline strength and low social category faultline distance. This hypothesis was supported. First, the interaction between social category faultline strength and distance was significantly related to bonuses. Second, task conflict (mediator) was regressed on the interaction between faultline strength and distance and found to be not significant. And third, there was a significant MeMo, not significant Me and interaction when task conflict was included in the HLM analyses on bonuses. Thus, in support of H6, the mediating moderation was confirmed for task conflict and identity on bonuses.

INSERT TABLE 3 HERE

\section{DISCUSSION}

In this study, we develop a theoretical framework for understanding how group faultlines affect 
group processes and outcomes in demographically diverse organizations. We extend the original faultline theory (Lau and Murnighan, 1998) by conceptualizing group faultlines as both (1) members' demographic alignment and (2) distance between aligned subgroups. We also advance theory by showing how different faultline bases (information-based and social category faultlines) have differential effects on outcomes. We contribute to the literature on conflict by examining the mediated moderating relationships between group faultlines, task conflict, and multiple individual-level outcomes using a sample of 76 workgroups from a Fortune 500 information processing company. Moreover, we investigate how organizational identity may shape the way, in which faultlines affect outcomes in groups, thereby adding to the literature on identity by studying identity in the context of intersubgroup relations. Finally, we contribute to the research on group composition by developing a more accurate faultline measure (the interaction between faultline strength score and the faultline distance score).

We found that members of groups with strong social category faultlines had low levels of individual performance outcomes (bonuses and performance ratings). These findings are consistent with Lau and Murnighan's (1998) model of faultlines and intragroup processes that suggests that subgroups are predictable from demographics. Members of groups with strong social category faultlines are more likely to affiliate themselves with their respective subgroups and be less concerned with their larger group success. In contrast, our findings demonstrate that members of groups with strong information-based faultlines are more likely to have high levels of individual performance ratings. This is in accordance with a cohort effect based on the classic experiments of Asch (1956) — having one other person agree with you, even when the two of you are in the minority may lead to less hesitation to voice your opinion rather than simply agreeing with the majority opinion when you feel it is wrong. This open and rich exchange of information leads to higher levels of performance in groups with strong informational faultlines than in groups with weak informational faultlines. We also stress the importance of a cognitive resource perspective in conceptualizing the effects of informational faultlines (in addition to support and cohort effects discussed by Asch, 1956). We argue and provide empirical evidence suggesting that such informational splits can operate in workgroups as "healthy divides" (Gibson and Vermeulen, 2003) that stimulate effective decision making processes and improve performance. However, we found no results for the effect of informational faultlines on satisfaction; this suggests that the processes underlying satisfaction and performance may be different. For 
example, information sharing in groups with informational faultlines may generate gains in decision quality and an increase in performance ratings, however, these exchanges can be accompanied by negative side effects and dissatisfaction because people may take things personally when debating divergent opinions (Jehn, 1995).

Our results demonstrate that the relationship between faultlines and outcomes is moderated by distance and is double moderated by strong team identity. As predicted, we found that faultline distance further exacerbated the negative effects in groups with strong social category faultlines and reversed the positive effects in groups with information-based faultlines. Our findings also confirm theoretical predictions developed based on the extension of the dual identity model (e.g., Dovidio, Kawakami, and Gaertner, 2001) to the case of multiple social identities and overlapping or cross-cutting categories (Brewer, 2000). The dual identity model posits that bias reduction may occur when group members share a common superordinate identity rather than consider themselves only as members of separate subgroups (Gartner and Dovidio, 2000). Our results suggest that members of subgroups formed by demographic faultlines may shift their identification towards the larger group and exhibit less polarization over divergent opinions due to such bias reduction.

Additionally, our results show that strong faultlines intensify task conflict within a group, which then also decreases satisfaction. In a recent meta-analytical study, De Dreu and Weingart (2003) showed that the positive effects of task conflict break down quickly when conflict becomes intense. Our findings support the argument that task conflict may interfere with cognitive flexibility and result in less satisfaction with group experience and performance. While much debate has been taking place in regard to whether task conflict is either beneficial (e.g. Jehn, 1995; Schulz-Hardt, Jochims, and Frey, 2002) or detrimental for performance (c.f., De Dreu \& Weingart, 2003), our study provides only a partial answer to this important question. Future studies should be designed to explore in finer detail the advantages or disadvantages of task conflicts in groups. Furthermore, the recognition that not one type of conflict but rather that the composition of all conflicts (the type of conflict present in a group relative to the other types of conflict present) within a group matters (Jehn and Chatman, 2000) provides another avenue for the future research on group composition, conflict, and performance.

The strengths of the current research (e.g., data collected from an actual workplace setting) are accompanied by potential weaknesses. Some limitations of this study are common in 
demography studies that use archival file data. First, while we were able to construct reliable measures of group process variables using content analysis of company documents, no direct measures of process variables were available. Future research should use employee survey data and interviews, if possible, to more fully understand how workgroup conflict and other process variables shape the effects of demographic faultlines. Next, as is regular in any archival study, our results are limited because of missing data. For example, due to turnover, new hires, and non-responsive employees, we could not attain complete responses from all group members in order to fully specify our process (conflict) and context (identity) variables. These are just a few limitations that are often associated with field studies using archival data collections. We believe our study has an advantage, however, over many archival studies because we did have useful and relevant text data on team processes, something most often missing in large archival datasets.

This study is fruitful because it provides one of the first empirical tests of group faultline theory and validates our predictions about the effects of demographic faultlines on conflict and performance. Evidence of these effects opens the door to future research of exploring group faultlines in diverse workgroups. One possibility is to investigate the differences in faultline dynamics with respect to the group size. For instance, in this study, we only look at subgroup splits, excluding one-person (token) splits. Faultline theory as developed by Lau and Murnighan (1998) suggests that two competing subgroups may generate much intensity due to diametric opposition to one another; we were interested in exploring these specific processes. However, future empirical research is needed to explore the differences between the effects of a group faultline which divides and excludes one person from the larger group in comparison to the effects of subgroup splits on the group processes and performance outcomes. Research on tokens and tokenism (Kanter, 1977) can provide a useful framework for this analysis. Due to the token's heightened visibility and exclusion from informal interactions with peers, group members will exaggerate differences between themselves and the tokens, thus interfering with group performance. We believe that the effects of token splits will produce and trigger more severe processes in group functioning than the effects of subgroups. Furthermore, future research should investigate the effects of group faultlines by taking into account the possibility that a diverse group may also split into three and more homogeneous subgroups resulting from demographic faultlines. Our faultline algorithm is able to calculate all possible splits, specifically, including and excluding one-person splits, and hence, it can be a crucial operational 
tool used in future research.

Another line of research is to investigate the effects of possible moderators and contextual factors; task interdependence, for example, is one of them. Certain groups may have such great faultline strength and large distances that the subgroups actually formed into isolated groups, cutting off contact with the other subgroup. Their perception of the original group may dissolve and merge with their subgroup identity. Consequently, interdependence might be severed and the subgroups have no reason to engage in conflicts with each other. This also raises the questions of when and how the group dissolves and what the factors are that trigger this adjournment. Our findings might have some important implications to the theory of group development by proposing an explanatory mechanism for group dissolution that has not been previously identified: a mechanism that explains how a larger group can dissolve into two isolated subgroups based on the alignment of group members along demographic lines.

Based on our results, we suggest that managers should be aware of the potentially harmful effects of faultlines that divide groups into homogenous subgroups along demographic lines. One way in which they may mitigate this risk would be to learn how to identify and overlook groups with a certain set of demographic characteristics that may encourage negative faultline dynamics. By identifying the diversity-motivated faultlines within a group, managers may predict and manage possible resultant conflicts. For example, they can facilitate open discussions of task conflicts and try to resolve relationship conflicts right away. Another possibility would be to stress similarities across existing subgroups resulting from faultlines and highlight the salience of positive group identity. This strong group identity may reduce perceived dissimilarities, consolidate group members around mutual goals, and eventually facilitate group performance and optimize overall productivity. In general, we believe that the development of group faultline theory has the potential to provide an integrative understanding of the functioning of diverse groups in organizational settings to enable people from diverse backgrounds to succeed in their work. 


\section{REFERENCES}

Allen, V.L. and J.M. Levine. 1971. Social support and conformity: The role of independent assessment of reality. Journal of Experimental Social Psychology, 7(1): 48-58.

Amason, A. 1996. Distinguishing the effects of functional and dysfunctional conflict on strategic decision making: Resolving a paradox for the top management teams. Academy of Management Journal, 39: 123-148.

Amason, A.C. and D.M. Schweiger. 1994. Resolving the paradox of conflict, strategic decision making, and organizational performance. International Journal of Conflict Management, 5: 239253.

Ancona, D.G. 1990. Outward bound: Strategies for team survival in the organization. Academy of Management Journal, 33: 334-365

Ancona, D. and D. Caldwell. 1992. Bringing the boundary: External activity and performance in organizational teams. Administrative Science Quarterly, 37: 634-665.

Asante, M. and A. Davis. 1985. Black and white communications: Analyzing workplace encounters. Journal of Black Studies, 16(1): 77-93.

Asch, S.E. 1956. Studies of independence and conformity: A minority of one against a unanimous majority. Psychological Monographs, 70(9) (No. 416).

Bantel, K.A. and S.E. Jackson. 1989. Top Management and innovations in banking: Does the composition of the top team make a difference? Strategic Management Journal, 10: 107-124.

Baron, R.M., N. Kerr, and N. Miller. 1993. Group Process, Group Decision, Group Action. Buckingham, UK: Open University Press.

Bettencourt, B.A., K.E. Dill, S. Greathouse, K. Charlton, and A. Mulholland. 1997. Evaluations of ingroup and outgroup members: The category-based expectancy violation. Journal of Experimental Social Psychology, 33: 244-275.

Blau, P. 1977. Inequality and Composition: A Primitive Theory of Social Structure. New York, NY: Free Press.

Bragg, B.W. and V. Allen. 1972. The role of the public and private support in reducing conformity. Psychonomic Science, 29(2): 81-82.

Brewer, M.B. 2000. Reducing prejudice through cross-categorization: Effects of multiple social identities. In S. Oskamp (ed.), Reducing Prejudice and Discrimination: 165-183. Mahwah, NJ: Erlbaum.

Byrne, D. 1971. The Attraction Paradigm. New York, NY: Academic Press.

Cramton, C.D. and P.J. Hinds. 2003. Subgroups dynamics in internationally distributed teams: Ethnocentrism or cross-national learning? Working paper, George Mason University.

Cummings, A., J. Zhou, and G.R. Oldham. 1993. Demographic differences and employees work outcomes: Effects of multiple comparison groups. Paper presented at the annual meeting of the Academy of Management, Altlanta, GA.

De Dreu, C.K.W. and M.A. West. 2001. Minority dissent and team innovation: The importance of participation in decision making. Journal of Applied Psychology, 86(6): 1191-1201.

Eisenhardt, K., J. Kahwajy, and L. Bourgeois. 1997. Conflict and strategic choice: How top management teams disagree. California Management Review, 39: 42-62. 
Ensari, N. and N. Miller. 2001. The out-group must not be so bad after all: The effects of disclosure, typicality, and salience on intergroup bias. Journal of Personality and Social Psychology, 83(2): 313-329.

Freidman, R.A. and J. Podolny. 1992. Differentiation of boundary spanning roles: Labor negotiations and implications for role conflict. Administrative Science Quarterly, 37(1): 28-47.

Gibson, C. and F. Vermeulen. 2003. A healthy divide: Subgroups as a stimulus for team learning behavior. Administrative Science Quarterly, 48: 202-239.

Gillespie, J.J., J.M. Brett, and L.R. Weingart. 2000. Interdependence, social motives, and outcome satisfaction in multiparty negotiation. European Journal of Social Psychology, 30: 779797.

Gruenfeld, D.H., E.A. Mannix, K.Y. Williams, and M.A. Neale. 1996. Group composition and decision making: How member familiarity and information distribution affect process and performance. Organizational Behavior and Human Decision Processes, 67(1): 1-15.

Hambrick, D., T. Cho, and M. Chen. 1996. The influence of top management teams heterogeneity on firms' competitive moves. Administrative Science Quarterly, 41: 659-684.

Hambrick, D.C., J T. Li, K. Xin, and A.S. Tsui. 2001. Compositional gaps and downward spirals in international joint venture management groups. Strategic Management Journal, 22(11): 10331053.

Hewstone, M., M. Rubin, and H. Willis. 2002. Intergroup bias. Annual Review of Psychology, 53: 575-604.

Hogg, M. 1996. Social identity, self-categorization, and the small group. In E. Witte and J. Davis (eds.), Understanding Group Behavior, Vol. 2: Small Group Processes and Interpersonal Relations: 227-253. Mahwah, N.J.: Lawrence Erlbaum Associates.

Hogg, M.A., J.C. Turner, and B. Davidson. 1990. Polarized norms and social frames of reference: A test of self-categorization theory of group polarization. Basic and Applied Social Psychology, 11: 77-100.

Insko, C.A., J. Schopler, B.M. Pemberton, J. Wieselquist, S.A. McIlraith, D.P. Currey, and S.L. Gaertner. 1998. Long-term outcome maximization and the reduction of interindividualintergroup discontinuity. Journal of Personality and Social Psychology, 75(3): 695-710.

Jackson, S.E., J.F. Brett, V.I. Sessa, D.M. Cooper, J.A. Julian, and K. Peyronnin. 1991. Some differences make a difference: Individual dissimilarity and group heterogeneity as correlates of recruitment, promotion, and turnover. Journal of Applied Psychology, 76: 675-689.

Jackson, S.E., A. Joshi, and N.L. Erhardt. 2003. Recent research on teams and organizational diversity: SWOT analysis and implications. Journal of Management, 29(6): 801-830.

Jehn, K.A. 1994.Enhancing effectiveness: An investigation of advantages and disadvantages of value-based intragroup conflict. International Journal of Conflict Management, 5: 223-238.

Jehn, K.A. 1995. A multimethod examination of the benefits and detriments of intragroup conflict. Administrative Science Quarterly, 40: 256-282.

Jehn, K.A. 1997. A qualitative analysis of conflict types and dimensions in organizational groups. Administrative Science Quarterly, 42: 520-557.

Jehn, K.A. and O. Werner. 1993. Hapax Legomenon II: Theory, a thesaurus, and word frequency. Cultural Anthropology Method, 5: 8-10. 
Jehn, K.A., G. Northcraft, and M. Neale. 1999. Why differences make a difference: A field study of diversity, conflict, and performance in workgroups. Administrative Science Quarterly, 44: 741-763.

Jehn, K.A. and J.A. Chatman. 2000. The influence of proportional and perceptual conflict composition on team performance. International Journal of Conflict Management, 11: 56-73.

Jobson, J.D. 1992. Applied Multivariate Data Analysis. Volume II: Categorical and Multivariate Methods. New York: Springer-Verlag.

Johnson, D.W. and F.P. Johnson. 1994. Joining Together: Group Theory and Group Skills. Boston, MA: Allyn and Bacon.

Lau, D. and J.K. Murnighan. 1998. Demographic diversity and faultlines: The compositional dynamics of organizational groups. Academy of Management Review, 23(2): 325-340.

Lau, D. and J.K. Murnighan. 2005. Interactions within groups and subgroups: The dynamic effects of demographic faultlines. Working paper, Northwestern University.

Mackie, D.M., T. Devos, and E.R. Smith. 2000. Intergroup emotions: Explaining offensive action tendencies in an intergroup context. Journal of Personality and Social Psychology, 79(4): 602-616.

Messick, D.M. and D.M. Mackie. 1989. Intergroup relations. Annual Review of Psychology, 40: 45-81.

Morrison, D.G. 1967. Measurement problems in cluster analysis. Management Science, 13(2): B-775-B-780.

Mortensen, M. and P.J. Hinds. 2001. Conflict and shared identity in geographically distributed teams. International Journal of Conflict Management, 12(3): 212-238.

Muller, D., Judd, C.M., and Yzerbyt, V.Y. 2005. When mediation id moderated and moderation is mediated. Working paper, University of Colorado at Boulder.

Nemeth, C.J. 1986. Differential contributions of majority and minority influence. Psychological Review, 93: 23-32

Offermann, L. R., and M.K. Gowing. 1990. Organizations of the future: Changes and challenges. American Psychologist, 45 (2): 95-108.

Pelled, L.H. 1996. Demographic diversity, conflict, work group outcomes: An intervening process theory. Organization Science, 7: 615-631.

Pelled, L.H., K.M. Eisenhardt, and K.R. Xin. 1999. Exploring the black box: An analysis of work group diversity, conflict and performance. Administrative Science Quarterly, 44: 1-28.

Phillips, K.W. 2003. The effects of categorically based expectations on minority influence: The importance of congruence. Personality and Social Psychology Bulletin, 29(1): 3-13.

Phillips, K.W., E.A. Mannix, M.A. Neale, and D.H. Gruenfeld. 2004. Diverse groups and information sharing: The effects of congruent ties. Journal of Experimental Social Psychology.

Polzer, J.T, L.P. Milton, and W.B. Swann Jr. 2002. Capitalizing on diversity: Interpersonal congruence in small work groups. Administrative Science Quarterly, 47(2): 296-324

Rink, F. and N. Ellemers. 2003. The cost and benefits of work style diversity and informational diversity on work process and work outcomes in task groups: A multi-method study. Working paper, Leiden University. 
Riordan. C.M. 2000. Relational demography within groups: Past developments, contradictions, and new directions. In G.R. Ferris (ed.) Research in Personnel and Human Resource Management, 19: 131-173. Oxford, UK: Elsevier Science Inc.

Schneider, B., A.N. Salvaggio, and M. Subirats. 2002. Climate strength: A new direction for climate research. Journal of Applied Psychology, 87(2): 220-229.

Schopler, J., C.A. Insko, K.A. Graetz, S.M. Drigotas, and V.A. Smith. 1991. The generality of the individual-group discontinuity effect: Variations in positivity-negativity of outcomes, players' relative power, and magnitude of outcomes. Personality and Social Psychology Bulletin, 17: 612-624.

Schweiger, D.M. and W.R. Sandberg. 1989. The utilization of individual capabilities in group approaches to strategic decision-making. Strategic Management Journal, 10(1): 31-44.

Schwenk, C.R. 1990. Effects of devil's advocacy and dialectical inquiry on decision making: A meta-analysis. Organizational Behavior and Human Decision Processes, 47: 161-176.

Sharma, S. 1996. Applied Multivariate Techniques. New York: John Wiley and Sons.

Swann, W.B., J.T. Polzer, D.C. Seyle, and S.J. Ko. 2004. Finding value in diversity: Verification of personal and social self-views in diverse groups. Academy of Management Review, 29(1): 927.

Tajfel, H. and J.C. Turner. 1986. The social identity theory of intergroup behavior. In Worchel and Austin (eds.), Psychology of Intergroup Relations: 7-24. Chicago, IL: Nelson-Hall.

Thatcher, S.M.B. and K. A. Jehn. 1998. A model of group diversity profiles and categorization processes in bicultural organizational teams. In M.A. Neale, E.A. Mannix and D.H. Gruenfeld (eds.), Research on Managing Groups and Teams: 1-20. Stamford, CT: JAI Press.

Thatcher, S.M.B., K.A. Jehn, and E. Zanutto. 2003. Cracks in diversity research: The effects of faultlines on conflict and performance. Group Decision and Negotiation, 12: 217-241.

Thomas, D.A. and R.J. Ely. 1996. Making differences matter: A new paradigm for managing diversity. Harvard Business Review, 74(5): 79-91.

Tsui, A.S., T.D. Egan, and C.A. O'Reilly. 1992. Being different: Relational demography and organizational attachment. Administrative Science Quarterly, 37(4): 549-577.

Wagner, W.G., J. Pfeffer, and C.A. O’Reilly. 1984. Organizational demography and turnover in top management groups. Administrative Science Quarterly, 29(1): 74-92.

Webber, S. and L. Donahue. 2001. Impact of highly and less job-related diversity on work group cohesion and performance: A meta-analysis. Journal of Management, 27(2): 141-162.

Williams, K. and C.A. O’Reilly. 1998. Demography and diversity in organizations: A review of 40 years of research. In B.M. Staw and L.L. Cummings (eds.), Research in Organizational Behavior, 20: 77-140. Oxford, UK: Elsevier Science Inc.

Wit, A.P. and N.L. Kerr. 2002. 'Me versus just us versus us all' categorization and cooperation in nested social dilemmas. Journal of Personality and Social Psychology, 83(3): 616-637. 
Appendix 1. An example of how to calculate Fau Distance.

\section{Total Sum of Squares and Fau}

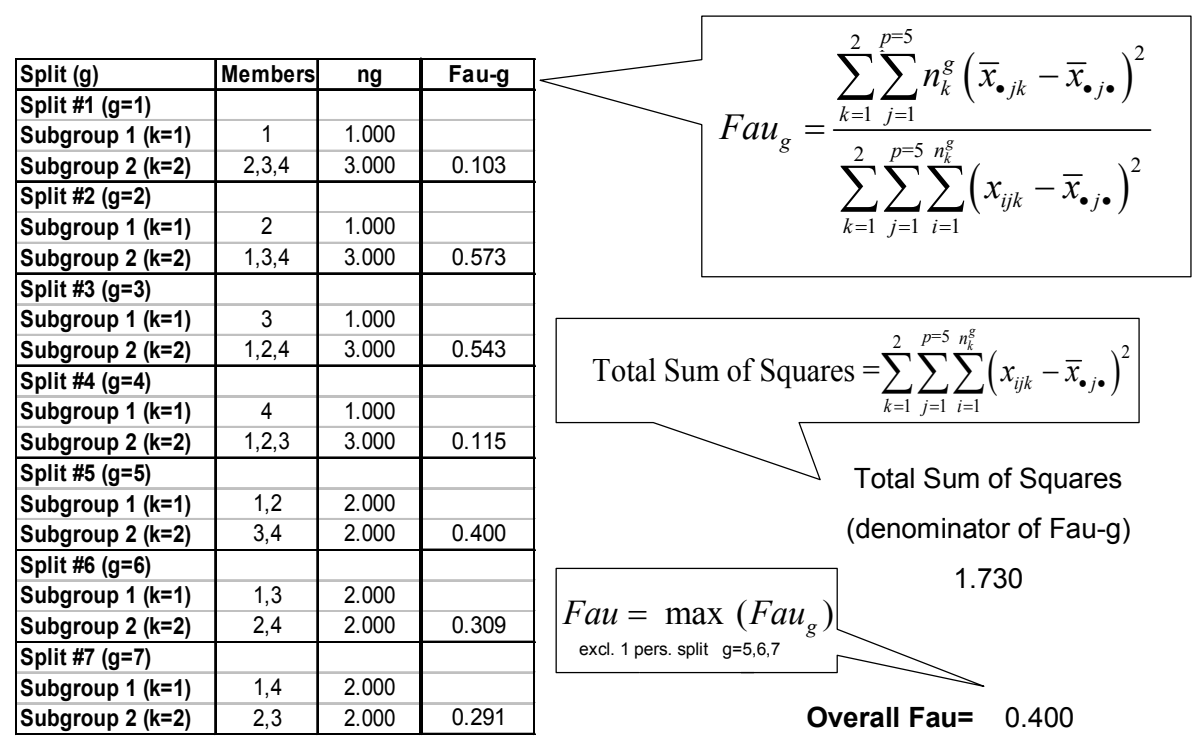

We calculate the ratio of the between group sum of squares to the total sum of squares as per Thatcher et al., 2003. The faultline strength, Fau, is calculated as the maximum value of $F_{a}$ over all possible splits $g=1,2, \ldots S$. (see above). Please note that in this study we considered only splits in which each subgroup has at least two members, that is $g=5,6$, and 7 . The faultline distance is then calculated as the maximum value of $D_{g}$ between centroids (the Euclidean distance between the two sets of averages) (see below).

\section{Distance}

\begin{tabular}{|l|c|c||c|}
\hline Split (g) & Members & ng & Distance-g \\
\hline Split \#1 (g=1) & & & \\
\hline Subgroup 1 (k=1) & 1 & 1.000 & \\
\hline Subgroup 2 (k=2) & $2,3,4$ & 3.000 & 0.238 \\
\hline Split \#2 (g=2) & & & \\
\hline Subgroup 1 (k=1) & 2 & 1.000 & \\
\hline Subgroup 2 (k=2) & $1,3,4$ & 3.000 & 1.321 \\
\hline Split \#3 (g=3) & & & \\
\hline Subgroup 1 (k=1) & 3 & 1.000 & \\
\hline Subgroup 2 (k=2) & $1,2,4$ & 3.000 & 1.251401 \\
\hline Split \#4 (g=4) & & & \\
\hline Subgroup 1 (k=1) & 4 & 1.000 & \\
\hline Subgroup 2 (k=2) & $1,2,3$ & 3.000 & 0.2655579 \\
\hline Split \#5 (g=5) & & & \\
\hline Subgroup 1 (k=1) & 1,2 & 2.000 & \\
\hline Subgroup 2 (k=2) & 3,4 & 2.000 & 0.6912553 \\
\hline Split \#6 (g=6) & & & \\
\hline Subgroup 1 (k=1) & 1,3 & 2.000 & \\
\hline Subgroup 2 (k=2) & 2,4 & 2.000 & 0.535005 \\
\hline Split \#7 (g=7) & & \multicolumn{1}{|l||}{} \\
\hline Subgroup 1 (k=1) & 1,4 & 2.000 & \\
\hline Subgroup 2 (k=2) & 2,3 & 2.000 & 0.503755 \\
\hline
\end{tabular}
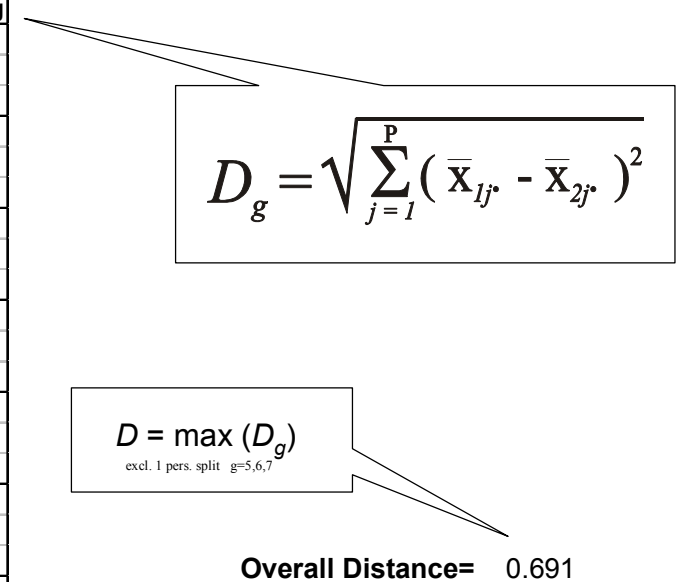
Appendix 2. Content analysis rules.

\section{CODING PROCEDURE:}

1. Three raters jointly go through the first 5-10 individual responses to develop the initial rules.

2. Then two raters go through all the responses to find extreme case examples (that is examples of approximately low and high conflict, identity, satisfaction, or satisfaction), to indicate the scale range.

3. The raters individually rate these examples.

4. Then to figure out the scale, the raters jointly discuss their scores for the above examples and sort out any discrepancies.

5. Next both raters independently rate 30 random responses to compare their responses, and then discuss these to sort out further differences. By now the raters should have a good sense of the scale and should achieve agreement on most scores, with a difference of no more than 1 for corresponding individual scores.

6. Finally, two raters score the rest of the responses.

\section{QUESTIONS FOR THE RATERS:}

What is the intensity of the task conflict? (Task Conflict)

To what extent does a group perform effectively according to the respondent? (Satisfaction)

To what extent does the group member identify with the group? (Identity)

\section{GUIDELINES}

- The unit of analysis is the entire individual response; use all context available in the response to arrive at the score.

- Base your decision on all relevant statements indicating the variable being scored; highlight the key sentences (ex. for identity: "...define and gain consensus on our key points of differentiation. Able to position more strongly who we are and what we stand for...")

- Assign missing values to a response that exhibits an unusually low level of comprehensibility due to incomplete or poor sentence structure, or grammar and spelling mistakes (e.g., the rater cannot understand what the person is saying)

- When scoring the response for the variable, first place it within a range of low/extremely negative to moderate/neutral (scores from 1-4), or moderate/neutral to high/extremely positive (scores from 4-7). Second compare the response to other responses with scores within the same range. Based on the comparison, choose the respective score for the response. 
Table 1. Means, Standard Deviations, and Zero-Order Correlations Among Variables.

\begin{tabular}{|c|c|c|c|c|c|c|c|c|c|c|c|c|c|}
\hline Correlations & $\begin{array}{c}\text { Mean } \\
(N= \\
567)\end{array}$ & $\begin{array}{l}\text { S.D. } \\
(N= \\
567)\end{array}$ & $\begin{array}{c}\text { Mean } \\
(N= \\
76)\end{array}$ & $\begin{array}{c}S . D \\
(N= \\
76)\end{array}$ & 1 & 2 & 3 & 4 & 5 & 6 & 7 & 8 & 9 \\
\hline 1. Informational Faultline Strength & .591 & .110 & .599 & .116 & & $.301 * *$ & -.049 & -.082 & $.265^{*}$ & -.004 & -.056 & .020 & .207 \\
\hline 2. Informational Faultline Distance & 1.723 & .481 & 1.676 & .497 & $.321 * *$ & & -.026 & -.019 & .169 & .214 & -.034 & .090 & .027 \\
\hline 3. Social Category Faultline Strength & .654 & .112 & .656 & .126 & -.056 & -.066 & & $.487 * *$ & -.217 & -.149 & .051 & -.088 & .023 \\
\hline 4. Social Category Faultline Distance & 1.623 & .467 & 1.609 & .532 & $-.115^{* *}$ & .004 & $.446^{* *}$ & & -.117 & -.070 & -.011 & -.206 & .097 \\
\hline 5. Performance Ratings & 3.910 & .749 & 3.894 & .379 & $.132 * *$ & $.116^{* *}$ & $-.090 *$ & -.025 & & $.407 * *$ & .067 & .204 & .137 \\
\hline 6. Bonuses & $\begin{array}{l}29827 . \\
890\end{array}$ & $\begin{array}{l}45195 . \\
577\end{array}$ & $\begin{array}{l}27558 . \\
018\end{array}$ & $\begin{array}{l}31004 . \\
574\end{array}$ & -.019 & $.175 * *$ & $-.108 *$ & -.051 & $.269 * *$ & & .045 & .033 & $.300 * *$ \\
\hline 7. Satisfaction & 3.119 & 1.042 & 3.019 & 1.006 & -.026 & -.036 & .039 & -.027 & .055 & .038 & & $.566 * *$ & $-.301 * *$ \\
\hline 8. Identity & -.693 & 2.619 & -.659 & 1.652 & .020 & .057 & .016 & -.070 & .072 & .005 & $.579 * *$ & & $-.381 * *$ \\
\hline 9. Task Conflict & 2.554 & 1.587 & 2.423 & 1.182 & .027 & .039 & -.068 & -.003 & .064 & $.218 * *$ & $-.350 * *$ & $-.321 * *$ & \\
\hline
\end{tabular}

$* \mathrm{p}<.05 ; * * \mathrm{p}<.01$

Individual level correlations are reported in the lower triangle.

Group level correlations are reported in the upper triangle. 
Table 2: HLM results (main effects and moderated distance hypothesis testing)

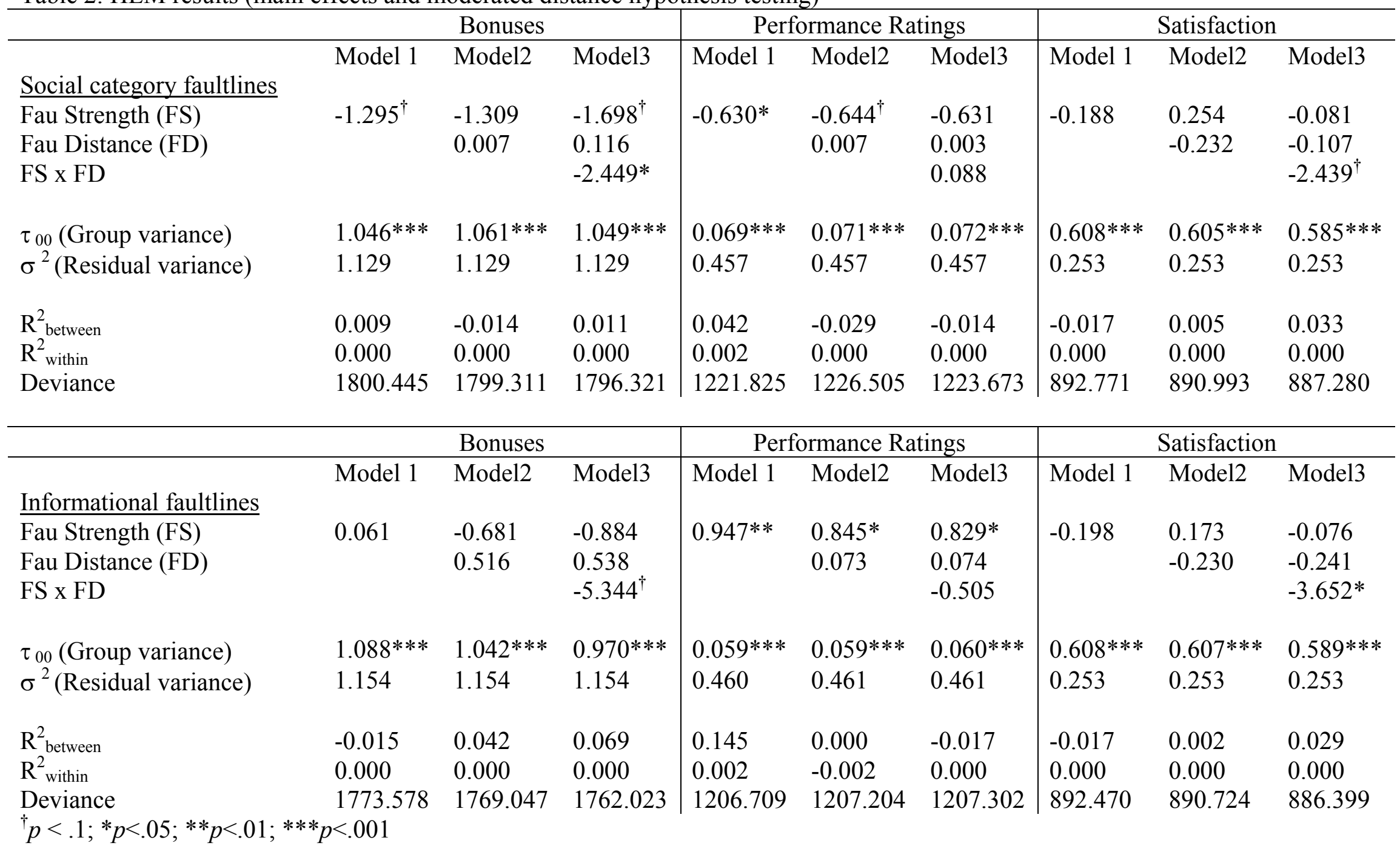


Table 3: HLM results (cross-level Mediated Moderation hypothesis testing)

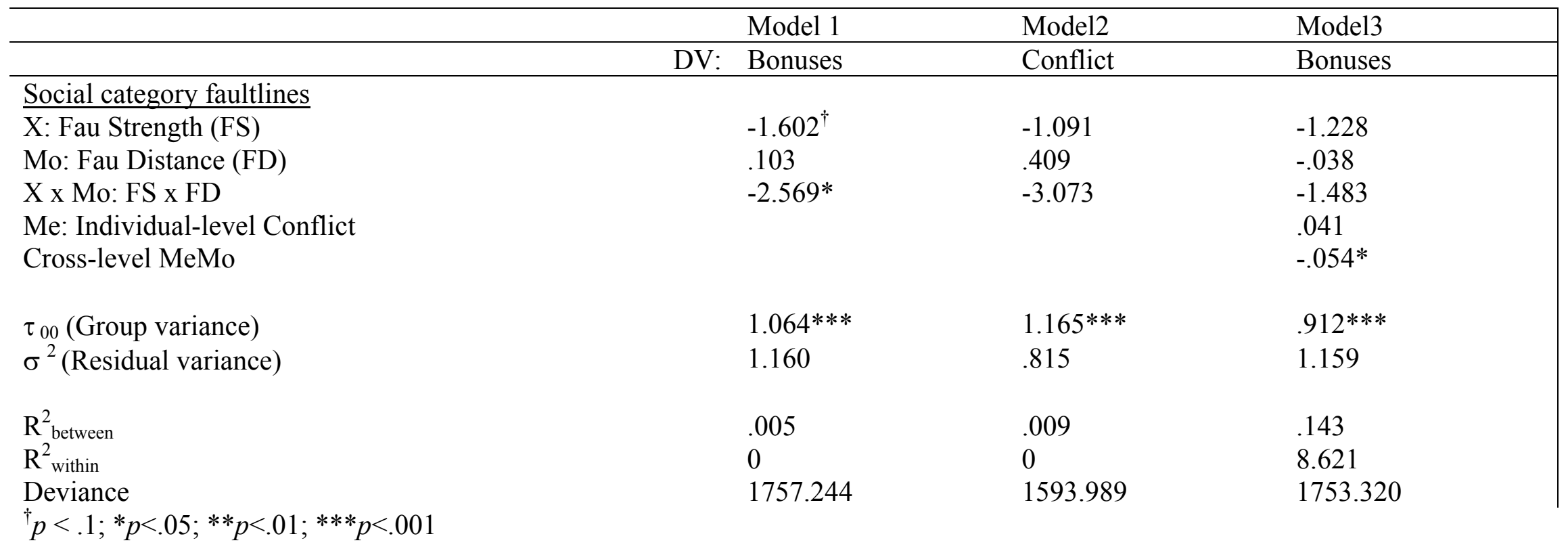


Figure 1: Interactions: Double Moderated Effect of Identity

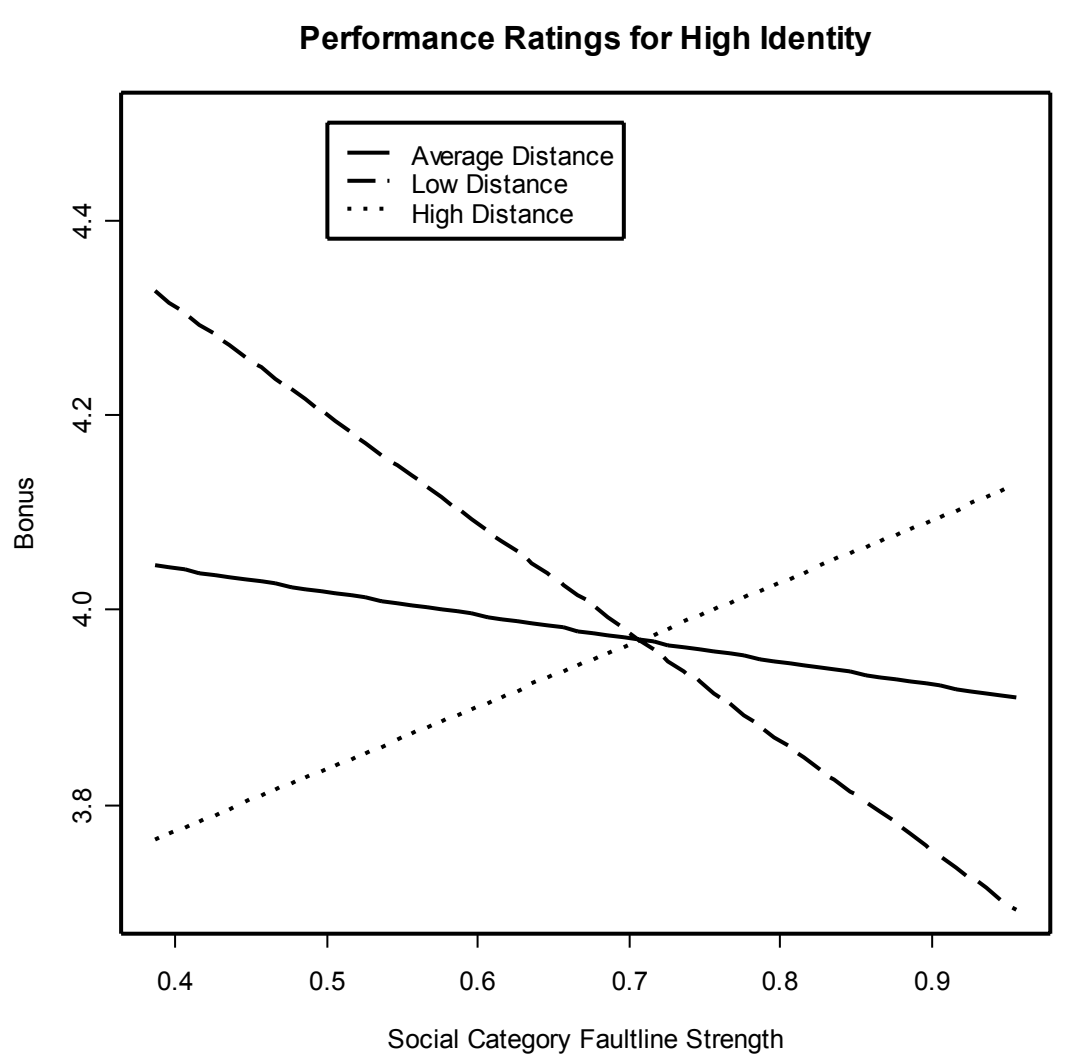

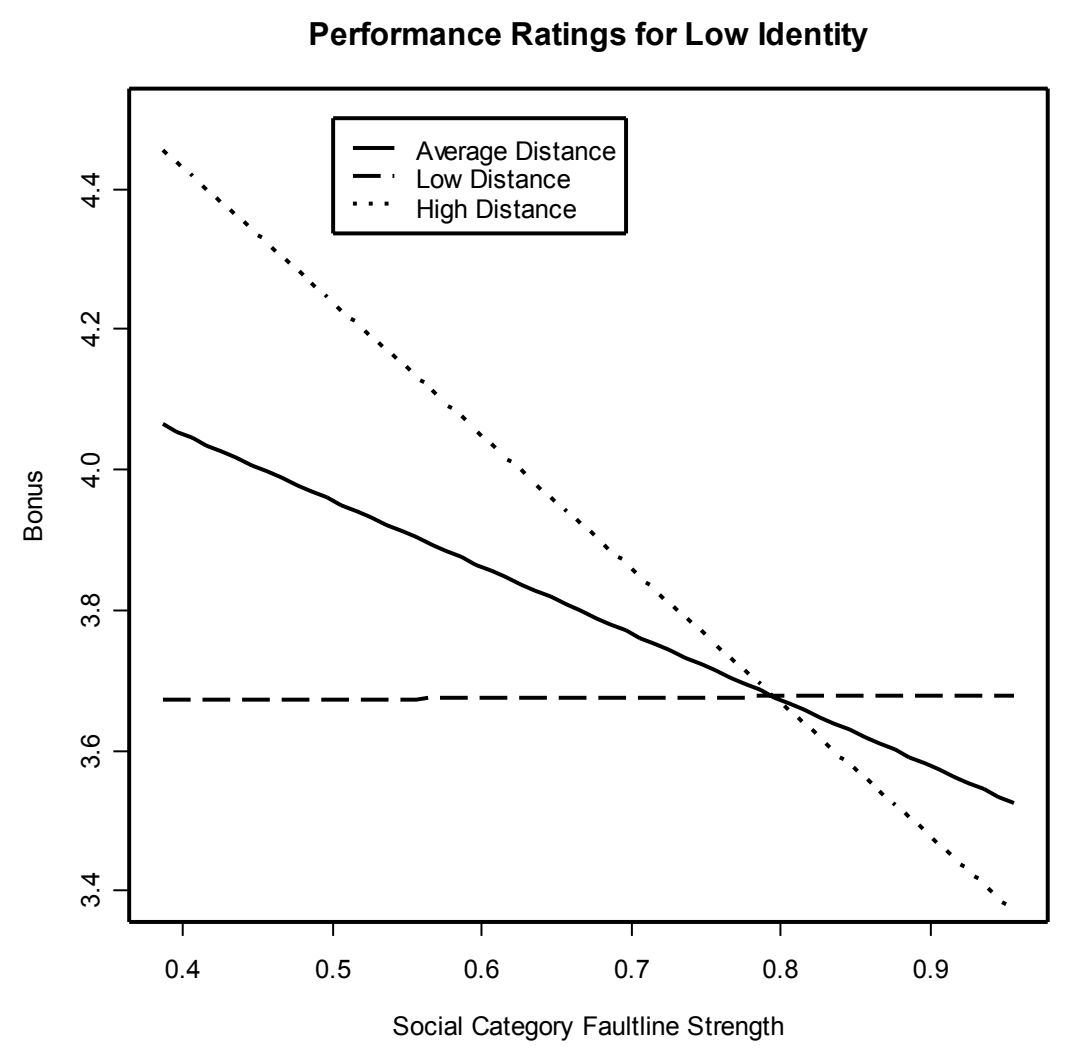

